\title{
El voto como "deber ser" y práctica política en espacios locales: una exploración de los relatos en torno a las Elecciones Municipales 2016
}

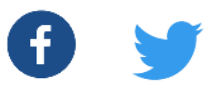

Vanessa Beltrán Conejo*

DOI 10.35242/RDE_2019_28_15

Nota del Consejo Editorial

Recepción: 24 de mayo de 2019.

Revisión, corrección y aprobación: 11 de junio de 2019.

Resumen: El artículo indaga en las narrativas y prácticas políticas de ciudadanas y ciudadanos habitantes de los cantones de Santa María de Dota, Puntarenas (central), Alajuela (central), San José (central) y Curridabat en torno al proceso electoral del 2016. La realización de entrevistas semiestructuradas a informantes clave permitió identificar los anclajes simbólicos entre el ejercicio del sufragio y los significados otorgados al concepto de ciudadanía y democracia. Desde los aportes de Robert Dahl y Guillermo O 'Donnell y la perspectiva teórica de los estudios críticos del discurso y producción de imaginarios políticos, fue posible establecer los puntos de encuentro y rupturas entre los relatos de las distintas comunidades. Se sostienen los hallazgos que vinculan el ejercicio del sufragio con los procesos históricos de identificación del "ser costarricense" aun cuando la práctica de los valores de la solidaridad y el diálogo- centrales en la producción discursiva de la nación- han perdido fuerza frente a prácticas cotidianas que los y las entrevistadas vinculan al individualismo.

Palabras clave: Participación política / Elecciones municipales / Valores democráticos / Idiosincrasia / Identidad ciudadana / Sociología política.

Abstract: The article searches the political narratives and practices of the citizens that inhabit the cantons of Santa Maria de Dota, Puntarenas (central), Alajuela (central), San Jose (central), and Curridabat around the 2016 electoral process. Semi-structured interviews made to key informants allowed the identification of symbolic anchoring between the exercise of suffrage and the meanings given to the concept of citizenry and democracy. From the contributions of Robert Dahl and Guillermo O'Donnell, and the theoretical perspective of the critical studies of the speeches and production of imaginary politicians, it was possible to establish the converging points and the ruptures among the relays of the different communities. The findings connect the exercise of suffrage with the historical processes of identification of "being Costa Rican", even though the values of solidarity and dialogue, key to the discursive production of the nation, have lost strength before the daily practices that interviewees link to individualism.

Key Words: Political participation / Municipal elections / Democratic values/ Idiosyncrasy / Citizen Identity / Political sociology.

\footnotetext{
* Costarricense, politóloga, correo beltran86@gmail.com. Licenciada en Ciencias Políticas de la Universidad de Costa Rica (UCR) y actualmente estudiante de la maestría en Género y Desarrollo de FLACSO, Sede Ecuador. Ha trabajado en el área de investigación desde el CIEP-UCR, en temas vinculados a la producción de subjetividad, derechos humanos y opinión pública. Ha estado vinculada a la Escuela de Ciencias Políticas de la UCR como docente y coordinadora de proyectos de acción social desde el 2016.
} 


\section{DERECHO ELECTORAL}

\section{INTRODUCCIÓN}

Doña Julia López es vecina del cantón de Curridabat desde hace más de 20 años y siempre que ha tenido la oportunidad de votar lo ha hecho porque "de eso vive la democracia" ${ }^{1}$ (comunicación personal, 5 de febrero del 2018). Esto se lo inculcó a sus hijos desde pequeños, así como el respeto por las reglas, el amor al trabajo, la honestidad y la solidaridad con los que tienen menos. A pesar de reconocer el voto como pilar constitutivo de nuestro sistema político, doña Julia nos comentó que en el Barrio La Lía -de donde es originaria ella y su familia- es muy poca la gente que vota en elecciones municipales.

Durante la entrevista que tuvimos con don Abel Rodríguez, vecino de Santa María de Dota, nos encontramos un panorama distinto: "acá todos participamos, y el acalde sabe que si hace las cosas bien lo vamos a apoyar, como ya lo hemos hecho. Él funciona bien porque nosotros lo tenemos bien controlado" (comunicación personal, 4 de febrero del 2018). Más adelante, don Abel nos comenta que él está seguro de que para que haya participación, las personas de la comunidad tienen que organizarse.

¿Qué nos dice esta información sobre la manera en la que las personas operacionalizan, desde la práctica, los principales sentidos comunes de la democracia? Este artículo se inscribe en la línea de investigación sobre subjetividades y discursos de la Unidad de Estudios de Opinión Pública del Centro de Investigación y Estudios Políticos (CIEP). A lo largo de 2 meses, entrevistamos a 20 personas de distintos cantones de las provincias de San José, Cartago, Puntarenas y Alajuela con perfiles sociodemográficos diferenciados, que dan cuenta de las diversas maneras en las que la ciudadanía se vincula con la institucionalidad local, la participación y las organizaciones políticas (nacionales y locales) a la luz de las elecciones municipales de 2016. Los datos preliminares que emergen de este estudio representan un primer acercamiento a otras formas de ingreso a los estudios electorales, a partir del análisis de la producción simbólica del voto y sus puntos de encuentro y de tensión con los discursos sobre la democracia y ejercicio de ciudadanía ${ }^{2}$. En este sentido, los hallazgos presentados en este

\footnotetext{
1 A lo largo del artículo se utilizan nombres ficticios para resguardar la confidencialidad de la información compartida a lo largo de las entrevistas realizadas.

${ }^{2}$ Esta investigación fue posible gracias al apoyo de las investigadoras María Fernanda Zumbado y Tracy Rivera, encargadas de la coordinación del trabajo de campo y parte de la aplicación de entrevistas y recopilación de datos.
} 


\section{DERECHO ELECTORAL}

texto acuñan relatos y experiencias relacionadas con el contexto municipal que conforman los discursos de personas como doña Julia y don Abel.

El análisis de estos textos reflejan que (1) los significados del voto y la percepción sobre los mecanismos de participación pueden variar en función de los contextos locales pero, en términos generales, comparten la reproducción de un sistema de valores vinculado a la protección individual de la libertad y el resguardo de la institucionalidad pública que sostiene el Estado de derecho costarricense ${ }^{3}$; 2) los discursos dominantes en cuanto a la participación electoral y democracia son concebidos como un pilar fundamental de la identidad nacional, aunque, al profundizar en las prácticas políticas de las personas entrevistadas, estos discursos se entremezclan con una sensación de desinterés y apatía con la institucionalidad democrática y estatal, y (3) la manera en cómo se vinculan las personas con las autoridades municipales y en general con el entorno comunitario se refleja en la cercanía - lejanía que reportan respecto de las elecciones. Esta vinculación debe entenderse desde las particularidades de cada uno de los relatos, la relación cotidiana que van construyendo las personas con su cantón y, sobre todo, las expectativas que depositan en las estructuras institucionales de Gobierno.

En una primera parte se sistematizan los principales debates teóricos en torno a este tema, así como los antecedentes centrales en el estudio de lo electoral desde su dimensión local. Seguidamente, se analizan los resultados de las entrevistas realizadas $y$, finalmente, en las conclusiones se discuten los hallazgos, limitaciones y nuevas líneas de investigación que surgen a raíz de este estudio.

\section{REFLEXIONES TEÓRICO-METOdOLóGICAS DE LA INVESTIGACIÓN}

\subsection{LA DEMOCRACIA LIBERAL COMO PROYECTO POLÍtico}

La producción del binomio liberalismo-democracia supone un fenómeno de amplias raíces históricas que retoma su crecimiento y profundización en el discurso político nacional hacia finales del siglo XX, en el marco del paradigma transicional que sustentó los procesos de democratización en Centroamérica.

Es pertinente destacar que los resultados aquí presentados no pretenden generalizarse al resto de la población. Se trata de una propuesta exploratoria que, a través de las narraciones de las y los entrevistados, enriquece los debates políticos y académicos sobre los procesos electorales locales.

${ }^{3}$ Esto apoya los hallazgos de investigaciones previas como las de Álvarez, L. 2010, 2014, 2018 y Díaz, J., 2014. 


\section{DERECHO ELECTORAL}

Los aportes de Robert Dahl y Guillermo O 'Donnell fueron centrales para darle vida a este proyecto político que se instaura en la región como una forma de organización social que se alimenta de sus instituciones y procedimientos. De ahí que las instituciones políticas y el Estado de derecho sean considerados un elemento central en la construcción discursiva de la noción de igualdad, eje central en este proyecto político.

O'Donnell toma algunos de estos elementos y desarrolla, como aspecto central de sus trabajos sobre democracia, la figura del Estado de derecho. Según el autor, este opera como estructura que legitima el accionar ciudadano y garantiza el ejercicio de la democracia como forma de organización política. La capacidad que tiene el Estado de derecho de asegurar, mediante mecanismos institucionales legales, los derechos fundamentales de la población, otorga a esta figura el protagonismo de los procesos de transición a la democracia, pues a través de él confluyen los elementos centrales del régimen: debate, participación y ciudadanía.

Al respecto Salazar plantea que:

Desde el discurso liberal la articulación entre el ejercicio de la ciudadanía y los mecanismos de elección y legitimación proporcionados por el sistema político, se da en función de las preferencias ciudadanas como supuesta expresión de su autonomía y móvil de sus elecciones. La democracia procedimental es una democracia de preferencias y la elección funciona como mecanismo legitimador de formas de poder basadas en la imagen de la representación como residuo de la participación. (2009, p. 126).

Los eventos electorales cobran así una fuerza vital que sostiene el entramado institucional mínimo del régimen democrático, al mismo tiempo que dotan de un sentido cívico e identitario la participación político-electoral de la ciudadanía a través del sufragio. Si bien estos significados se encuentran aún presentes en el discurso nacional, hoy vale la pena indagar en las fracturas y líneas de fuga de este complejo constructo simbólico. Estas grietas, que se traducen en aumentos del abstencionismo, desencanto con la política y aumento de la disposición hacia prácticas autoritarias, responden a un proceso de vaciamiento relativo y parcial del sentido de democracia, en la medida en que se han venido erosionando las condiciones materiales mínimas que le dan coherencia, no solo como sistema político, sino también como forma de organización de relaciones sociales inclusivas, participativas y libres. El trabajo 


\section{DERECHO ELECTORAL}

empírico que sustenta esta afirmación es señalado en el siguiente acápite (La dimensión simbólica de la democracia: apuntes metodológicos sobre los estudios del discurso).

Los marcos de sentido sobre los que operan las prácticas políticas hoy distinguen tensiones entre los discursos nacionales históricamente vinculados a una manera del "ser costarricense" y los efectos de un proceso de producción estatal que no ha logrado cumplir las expectativas ciudadanas sobre el régimen político por igual en todo el territorio. Si bien tenemos un amplio acceso al análisis de las elecciones históricas de los y las votantes, poco conocemos sobre las rutas que llevan a estas personas a tomar la decisión de participar o abstenerse. Es ahí donde el análisis de los discursos y las prácticas políticas de las personas generan un aporte importante. Para este caso de estudio en particular, se parte de la premisa de que las tendencias presentadas en cuanto a participación y abstención electoral en el ámbito local pueden ser analizadas también desde la manera en la que esta decisión -de votar o abstenerse de hacerlo- se va produciendo y reproduciendo en los diferentes espacios en forma de relatos.

\subsection{LA dimensión SIMBóliCa de LA Democracia: Apuntes metodológicos SOBRE LOS ESTUDIOS DEL DISCURSO}

El acercamiento político de los sujetos con el ámbito local, objeto central del artículo, se realiza a partir del método de análisis crítico del discurso (ACD) y comprende dos niveles de estudio: un primer nivel de carácter retórico vinculado a las construcciones narrativas de los conceptos, valores y relaciones entre democracia, participación y ciudadanía; y un segundo nivel relacionado con los relatos sobre prácticas en donde es posible estudiar el rango de aplicación del primer nivel de análisis.

En términos teórico-metodológicos, este trabajo utiliza el concepto de discurso acuñado por autores como Fairclough (2010) y los seguidores de la corriente crítica, quienes lo definen como una producción de sentido, constituida y constituyente del orden social, de carácter dinámico con capacidad de transformación. En este sentido, lo que vamos a entender por discurso al momento de analizar los datos empíricos del trabajo de campo va más allá del componente retórico, y más bien suma a estas narrativas el relato de las prácticas descrito por los sujetos entrevistados. 


\section{DERECHO EIECTORAL}

El espacio comunitario, en su dimensión territorial, necesariamente impregna y atraviesa las construcciones discursivas y las prácticas políticas. Así, el constructo histórico de identidad nacional que nos hace creer que el voto, la municipalidad y la comunidad significan lo mismo para todas las personas, se resquebraja al momento de atender los lugares, las formas y las narrativas que enuncian los sujetos. Esta perspectiva abre múltiples posibilidades para entender la complejidad que subyace en las relaciones de las personas con el sufragio, con las estructuras municipales y con la institucionalidad pública en general.

Tomando en cuenta que el inicio del trabajo de campo se llevó a cabo en diciembre del 2017 (casi dos años después del proceso electoral) el reto se tradujo en encontrar la manera de recabar experiencias que dieran cuenta, no solo de las historias relacionadas con la elección, sino también con la manera en la que se ha producido, y se produce actualmente, el tejido político de las comunidades que visitamos. Además de analizar el componente retórico -ese que se sostiene de constructos simbólicos muchas veces asociados al discurso hegemónico sobre identidad nacional- se incorporó el análisis de las prácticas y relaciones cotidianas de las personas, pensadas a través de 3 ámbitos de interacción: familia, comunidad y Gobierno local ${ }^{4}$.

Tabla 1

Distribución de entrevistas por cantón

\begin{tabular}{lll}
\hline Criterio de selección & Lugar & $\begin{array}{c}\text { Cantidad de } \\
\text { entrevistas } \\
\text { realizadas }\end{array}$ \\
\hline Alta participación -fuera del GAM- & Santa María de Dota & 5 \\
\hline Mediana participación -zona costera- & Puntarenas, cantón central & 4 \\
\hline $\begin{array}{l}\text { Poca participación -partido local } \\
\text { consolidado en el Gobierno municipal- }\end{array}$ & Curridabat & 3 \\
\hline Poca participación -dentro de la GAM- & Alajuela, cantón central & 4 \\
\hline & San José, cantón central & 4 \\
\hline
\end{tabular}

Nota: CIEP, 2018.

\footnotetext{
${ }^{4}$ Esta propuesta sugiere incorporar la dimensión territorial a la investigación. Aun cuando las categorías de análisis reflejan de manera indirecta un abordaje sobre la construcción social del espacio desde donde hablan las personas entrevistadas, es importante señalar que por una cuestión de tiempo y recursos no fue posible profundizar en las dinámicas políticas, económicas y socioculturales que caracterizan a cada una de las comunidades visitadas. Esto abre la posibilidad de generar nuevos estudios que se elaboren en torno a esta dimensión territorial.
} 


\section{DERECHO ELECTORAL}

\section{TRAYECTORIAS ACADÉMICAS EN EL ESTUdIO DE LA DEMOCRACIA Y LA PARTICIPACIÓN POLÍTICA EN COSTA RICA}

Aun cuando gran parte de la literatura en torno a los procesos electorales en Costa Rica hace referencia al estudio de la participación y abstención en el ámbito nacional, los aportes de este material en cuanto a estrategias metodológicas, hallazgos y recomendaciones se convierten en líneas base de este estudio. Interesan, sobre todo, aquellos resultados que profundizan en la cultura política y el comportamiento del electorado en términos de su interpretación de los conceptos de democracia y ciudadanía, su vinculación con la política, las relaciones que establecen con las estructuras partidarias y las personas candidatas ${ }^{5}$.

Desde la ciencia política, pero también desde la psicología y la sociología, se han desarrollado gran parte de los estudios de participación y abstención en Costa Rica6. Para efectos de esta investigación interesan los abordajes propuestos por Mora (2014) y Díaz (2010 y 2014) que profundizan en las prácticas políticas de los sujetos y posteriormente analizan su vinculación con la participación político-electoral.

Alfaro y Gómez (2017) abordan estos temas en el marco del proceso electoral municipal del 2016 y reflejan una conclusión similar en cuanto al comportamiento del abstencionismo: al hacer un seguimiento longitudinal de la participación electoral se evidencia que la mayoría de las personas han votado la mayoría de las veces y que, contrario a lo que sucede en elecciones nacionales, en el contexto local los cantones rurales presentan mayor participación.

Con el objetivo de ahondar en la producción de estas grietas entre el imaginario político democrático y el acercamiento práctico que reportan las personas frente a la política, han surgido importantes esfuerzos académicos nacionales que pretenden estudiar este fenómeno y su relación con la

\footnotetext{
${ }^{5}$ En este artículo no se utilizará el enfoque de cultura política, sino más bien el de estudios del discurso. Esta diferenciación será abordada en la sección teórica; sin embargo, interesan los trabajos de cultura política en el marco de los estudios electorales, pues reflejan resultados que dan cuenta de algunas formas de aproximación, valores y conductas de las personas respecto de este tipo de estructuras y eventos políticos.

${ }^{6}$ Ver: Alfaro, R. y Gómez, S (2016); Cascante M. J y Pignataro, A. (2017); Díaz, J. A (2014); Díaz y Solís (2010); Mora, S. et.al. (2014); Pignataro A. y Treminio, I. (2015); Programa Estado de la Nación (2017); Raventós C. et.al (2005) y Rodríguez, J. (1990).
} 


\section{DERECHO ELECTORAL}

presencia, o ausencia, de actitudes autoritarias en la población costarricense ${ }^{7}$. En su artículo, Mora y otros evidencian que en los resultados del estudio:

...se encuentra la marcada predisposición al autoritarismo reflejada en una gran parte de la población costarricense -a pesar del alto respaldo a la democracia- y el hecho de que las personas que apoyan la democracia y respaldan mayoritariamente las actitudes autoritarias poseen una concepción más materialista, utilitarista e individualista de la democracia que quienes apoyan la democracia y tienden más al rechazo de las actitudes autoritarias. (2014, p. 37).

A grandes rasgos, los estudios realizados en Costa Rica vinculados a la investigación de lo electoral dan cuenta de que los significados y prácticas políticas registradas en regiones como la Gran Área Metropolitana surgen de condiciones históricas, políticas y culturalmente distintas a aquellas que se registran en otras regiones del país, específicamente en los espacios rurales.

A pesar de las particularidades que emergen en los discursos sobre democracia, existe una serie de sentidos comunes compartidos entre las distintas regiones del país, que vale la pena indagar. Tal y como lo plantea Hermann Güendel, la producción del imaginario político costarricense ha estado históricamente vinculada a los procesos de formación y transformación de Estado: "Un imaginario nacional es ante todo una región del universo ideológico de la sociedad que incide como elemento determinador de una nacionalidad específica" (2009, p. 29). Para este estudio interesa analizar lo que Güendel denomina un segundo momento de reconfiguración del imaginario político nacional. Este se consolida hacia la segunda mitad del siglo XX con la construcción simbólica de la relación patria/democracia en el marco de la fundación de la Segunda República .

Ese modelo de Estado, que supone a su vez un significado de la manera en la que se constituye la democracia y el ejercicio ciudadano en Costa Rica a partir

\footnotetext{
${ }^{7}$ Es importante mencionar que las investigaciones como las que se realizan desde el IDESPO de la Universidad Nacional, el Programa Estado de la Nación y el Programa Naciones Unidas para el Desarrollo utilizan la noción de actitudes autoritarias y se refieren al análisis de las prácticas cotidianas de las personas entrevistadas y no necesariamente al apoyo o rechazo explícito que estos sujetos establezcan respecto a uno u otro régimen político. ${ }^{8}$ El trabajo de este autor forma parte de una amplia tradición historiográfica que gira en torno al estudio de los discursos e imaginarios que atraviesan las identidades nacionales. Ver: Láscaris, C. (1992); Molina I. y Palmer, S. (2000); Acuña, V. (2000) y Díaz (2016), entre otros autores de las disciplinas vinculadas a la historia, la sociología y la ciencia política.
} 


\section{DERECHO ELECTORAL}

de este periodo, se sustentaba en los principios de la social democracia y se vinculaba directamente al florecimiento de los Estados de bienestar. Sojo retoma esta construcción y destaca que: "Así funcionaron las cosas, funcionaron en lo político y en lo social porque de modos diversos se instaló la potente idea de la semejanza sobre la realidad de la desigualdad social" (2006, p.110).

Esta interacción de los ámbitos económicos y políticos permeó directamente la producción del discurso democrático ligado al imaginario político liberal. El respeto por la institucionalidad pública como fuente de justicia, materializada en la figura del Estado de derecho, fue uno de los núcleos centrales del discurso democrático costarricense que nos alcanza incluso en la actualidad. Sumado a lo anterior, el resguardo y protección de los derechos individuales y la propiedad privada fueron sellando las conductas políticas deseables del ser costarricense y se decantaron en las estructuras institucionales y normativas de base.

Así, mientras se fortaleció la base de un Estado social de derecho sostenido, fundamentalmente, en el fortalecimiento de una noción de clases medias, este rasgo común de semejanza elaborado por Sojo fue instaurándose en el discurso dominante de la nación -eminentemente vallecentralino-, Álvarez (2010, 2015 y 2018) determina que esta construcción, lejos de ser un fenómeno contemporáneo, se vincula con los procesos de formación de Estado y producción de ciudadanía, particularmente a inicios del siglo XX.

\section{Relatos Y PRÁcticas políticas en dimensión local: PRINCIPAles RESULTADOS}

Al inicio del artículo presentamos algunos extractos de las conversaciones que tuvimos con doña Julia en Curridabat y con don Abel en Santa María de Dota. Aun cuando ambos compartían una noción similar respecto de la importancia del voto como componente esencial de la identidad costarricense, cada uno convive en un contexto local en donde las relaciones con la comunidad y las autoridades municipales se construyen de maneras muy diferentes $y$, por lo tanto, el conjunto de apreciaciones y decisiones que les llevan a involucrarse o distanciarse de la vida política del cantón varían. 


\section{DERECHOELECTORAL}

\subsection{El "IGUALITICO" COMO UN MITO QUE LUCHA POR SOBREVIVIR}

Las entrevistas realizadas en los cantones de Santa María de Dota y Puntarenas nos dejan ver dos realidades locales que a primera vista parecen ser muy distintas. En la primera comunidad perdura una confianza en la institucionalidad pública y una cercanía con las autoridades locales que motiva a las personas a participar de las elecciones municipales. En la segunda, se refleja una constante sensación de descontento y lejanía con las estructuras gubernamentales que desincentiva la participación de las personas en el evento electoral. Tal como nos comentó doña Mercedes Vargas "¿Para qué vamos a ir a votar por un alcalde que ni se acuerda del pueblo que lo elige? Yo no creo en eso de la política, porque aquí en Puntarenas solo sirve para pedir votos" (comunicación personal, 5 de febrero del 2018).

Por su parte, don Pedro Monge, vecino de Santa María de Dota, nos mencionaba que ahí todos conocían a las personas de la municipalidad y que para él era más fácil controlar a las autoridades locales que al Gobierno central (comunicación personal, 20 de marzo del 2018). A raíz del análisis de las 9 entrevistas que componen el bloque de Puntarenas y Santa María de Dota es claro que la relación que establecen los sujetos con las autoridades locales y la política en general está supeditada al acceso a condiciones mínimas de seguridad, particularmente en el ámbito del trabajo, la alimentación y la salud. También es clave que en ambas localidades las personas tienden a vincularse más con sus vecinos. La figura 1 muestra una síntesis de los principales núcleos discursivos encontrados en las entrevistas de Puntarenas y Santa María de Dota. 


\section{DERECHOELECTORAL}

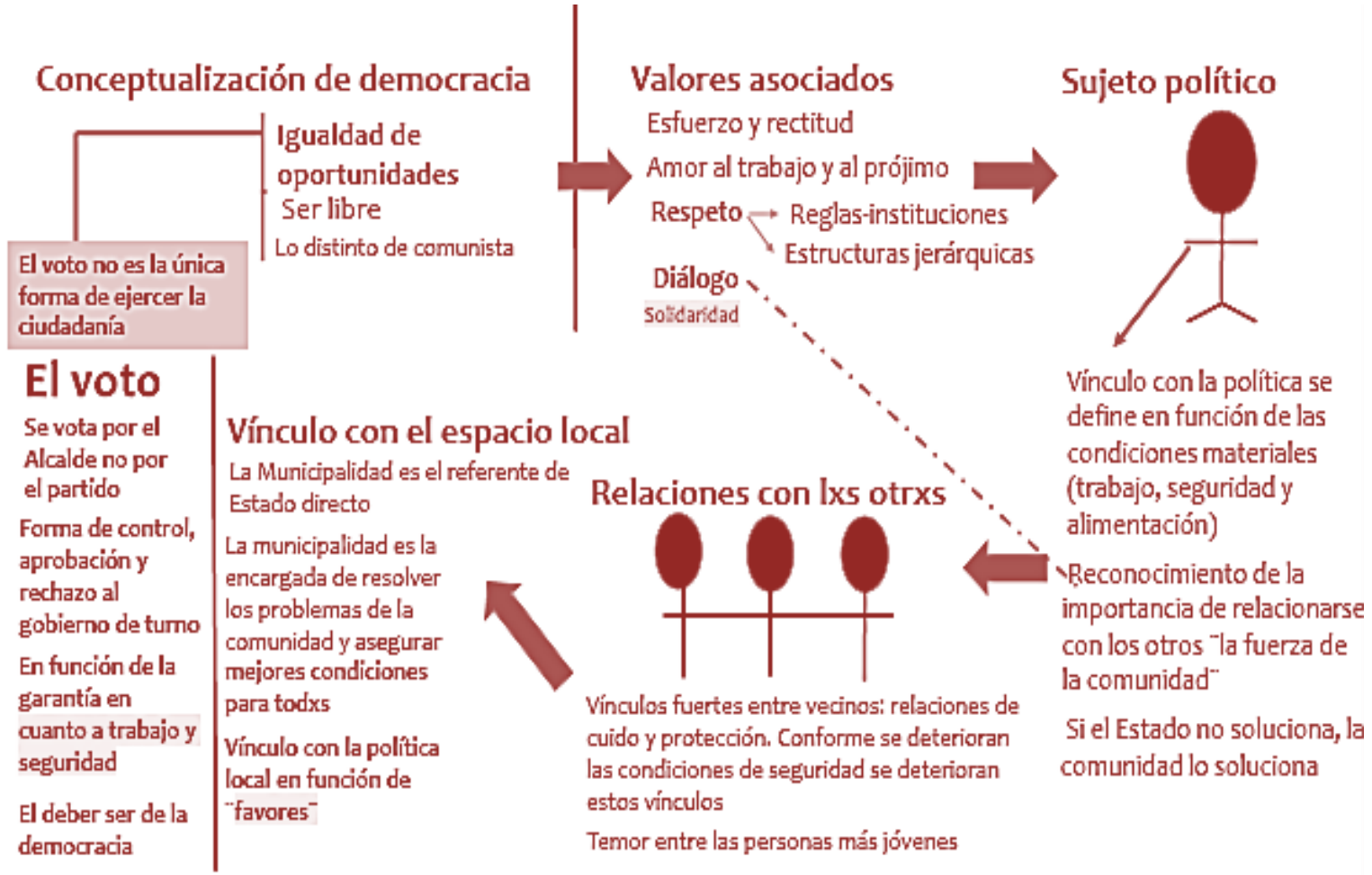

Figura 1. Principales núcleos discursivos para las entrevistas efectuadas en Santa María de Dota y Puntarenas. Elaborado con base en la información del CIEP, 2018.

Tal como se presenta en el diagrama, permanece una noción general de que el voto es el único mecanismo de ejercicio ciudadano, un "deber ser" de la democracia. Aquí surge un elemento de interés que se presenta en las entrevistas de ambos lugares: a pesar de que la igualdad se mantiene como un imaginario social que vincula a las personas de la comunidad y sostiene el porqué de la democracia, conforme se van deteriorando las condiciones materiales de seguridad, este imaginario se diluye frente a la necesidad de protección y beneficio individual.

Así, la tensión entre una deseabilidad de igualdad como pilar de convivencia en contextos de inseguridad, desempleo y falta de oportunidades que separan y compartimentan las relaciones sociales locales genera un tipo de vinculación compleja con los relatos históricos sobre democracia y participación política a la luz de las realidades concretas en las que estas personas producen su ciudadanía. La esperanza de que quien llegue a ocupar la alcaldía favorezca al barrio o a los vecinos cercanos es un núcleo discursivo reiterado como motivación para asistir a votar. 


\section{DERECHO EIECTORAL}

A pesar de los distanciamientos, apatía y desencanto que denotan las personas entrevistadas con la política, la municipalidad continúa siendo un referente del "gobierno" mucho más cercano que el Gobierno central. En ese sentido, le demandan no solo la posibilidad de asegurar condiciones infraestructurales y servicios de calidad (buenas carreteras, servicio de recolección de basura, seguridad comunitaria), sino que también la asocian con una estructura con capacidad de generar mejores condiciones para el desarrollo de la comunidad (opciones de empleo, acceso a servicios de salud y educación, entre otros).

Permanecen instalados los valores del respeto por la autoridad y la institucionalidad pública. Aunque no participan con regularidad en los procesos electorales, la democracia continúa enraizada como pilar fundamental de la identidad política de estas personas. Sin embargo, llama la atención que en algunos casos estos valores son trasladados a la práctica justificando conductas que reflejan una disposición a actitudes autoritarias: "Yo a mis hijos los educo para el respeto y el trabajo, pero sobre todo el respeto. A la autoridad hay que respetarla, en eso mi esposo y yo insistimos para que ellos crezcan bien, y sean buenos ciudadanos" (L.P., comunicación personal, 15 de marzo del 2018). Ser buen ciudadano implica ser respetuoso de las reglas que se reproducen desde el ámbito familiar hasta en el espacio público de las relaciones cotidianas.

\section{2 "Si NO SE METEN CONMIGO, YO NO ME METO CON NADIE": CIUDADANÍA Y DEMOCRACIA DESDE LAS ZONAS URBANAS}

La figura 2 muestra los resultados a partir de la lógica de análisis sobre la cual fueron construidas las entrevistas. En un primer momento se detalla la conceptualización de democracia esbozada por las personas entrevistadas. En un segundo momento de la conversación se ahonda en la manera en cómo ellas y ellos producen el sujeto político democrático -el ciudadano-, y de qué manera interactúa en espacios colectivos (particularmente visto en dinámicas familiares y comunitarias). Este abordaje conduce al análisis de cómo interactúan los sujetos en relación con las y los otros, así como su vínculo práctico con el espacio local. En la totalidad de los casos, esta última etapa de 
la consulta conllevó profundizar sobre el ejercicio del voto y su vínculo con la democracia, entendida desde la esfera local ${ }^{9}$.

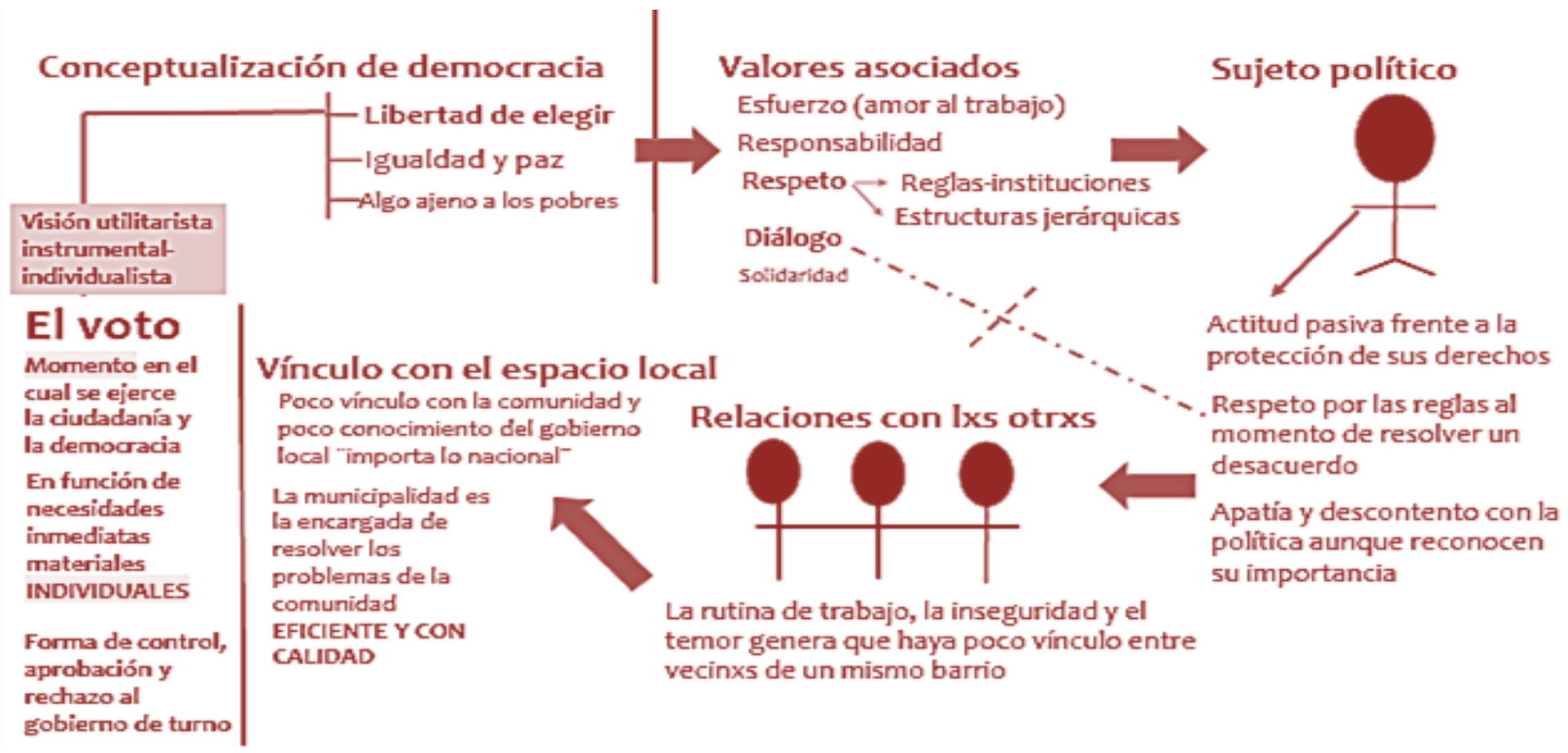

Figura 2. Principales núcleos discursivos para las entrevistas efectuadas en San José, Curridabat y Alajuela. Elaborado con base en la información del CIEP, 2018

Indistintantemente de si estábamos en Curridabat, San José o Alajuela, la reproducción de la "libertad de elegir" como pilar de la democracia fue recurrente en todas las entrevistas. Por encima de la noción fundante de igualdad y paz (que también ha sido parte de la construcción simbólica de la democracia costarricense) la libertad de las personas parece ser el pilar fundamental con el que se asocia esta forma de gobierno.

¿Cuáles valores o conductas asocian las personas con el ser democrático? Sin mucha pausa y con gran seguridad las personas entrevistadas mencionaron el respeto a las reglas y a la autoridad como principales actitudes esperables de alguien que vive en democracia. Las conductas culturalmente asociadas al deber ser costarricense también salieron a flote en esta fase de la entrevista: "Acudir al diálogo para mantener la paz", "amar el trabajo y esforzarse

\footnotetext{
9 Es importante destacar que, si bien existen referencias a la coyuntura local del 2016, la mayoría de las afirmaciones no necesariamente se vinculan a partir de la experiencia de las personas en este proceso particular, sino más bien se construyen desde la manera en la que ellas y ellos entienden lo local, la democracia y el ejercicio ciudadano desde el relato y la práctica. De tal manera que, si bien pueden aplicarse algunos de estos hallazgos en la aproximación al proceso electoral 2016, estos no pueden presentarse como explicaciones del comportamiento electoral de los sujetos en ese momento.
} 


\section{DERECHO ELECTORAL}

siempre en él" $y$, en menor medida, "aplicar la solidaridad con las personas que lo necesitan" fueron algunas de las frases que se registraron en estas conversaciones. La reiteración del respeto por las reglas y la autoridad se mantiene congruente en todas las conversaciones y pareciera que se asocia con el arraigo de la idea de Estado de derecho costarricense como estructura institucional que respalda y protege la democracia en el país.

Al momento de narrar las prácticas cotidianas de las personas entrevistadas en sus familias y su comunidad se vislumbran algunos puntos de tensión respecto de las nociones anteriormente descritas. Esta idea de libertad con la que se construye la democracia se decanta por posturas tendientes al individualismo respecto de la manera en la que se produce ciudadanía desde la práctica. Así, la apelación al diálogo y la solidaridad como valores vinculados a la democracia quedan en un segundo lugar y la emergencia de la idea de libertades individuales toma protagonismo: "Diay, mientras no se metan conmigo yo no me meto con nadie. Como le digo, lo mejor es no meterse en la vida de los otros y así evitar problemas" (M.S., comunicación personal, 21 de marzo de 2018).

Los relatos de doña Ana Rojas, de Alajuela, denotan algunos rasgos importantes por destacar sobre cómo se constituye ella como ciudadana. En la conversación nos comenta que realmente se interesa poco en la realidad política de su comunidad porque, además, "entre la rutina del cuido de los hijos, la familia y el trabajo, no queda tiempo ni energía para ponerse en esas de la política" (Rojas, 2018). Al mismo tiempo que aduce la importancia de que la ciudadanía fiscalice y controle lo que hacen "las autoridades locales" nos cuenta que su descontento con la política ha generado que le interese muy poco participar. A este punto, lo que señalan Pignataro y Cascante en su trabajo sobre elecciones presidenciales 2014 cobra relevancia y se posiciona la noción de delegación política al ejercicio ciudadano.

Las dinámicas laborales, las rutinas familiares y la inseguridad han generado una separación importante de los sujetos con su entorno inmediato y esto se traduce, necesariamente, en un posicionamiento de defensa de sus derechos individuales antes que aquellos relacionados con lo colectivo. En el ámbito de su relación con los otros, es recurrente la mención al problema de la inseguridad ciudadana que genera que cada vez más las personas se encierren en sus casas y se relacionen poco o nada con sus vecinos y su comunidad. El no conocer "al otro" parece alimentar la sensación de temor y desconocimiento del espacio comunitario que se habita, y se posiciona con más fuerza la idea de que la protección de derechos, la seguridad comunitaria, y el 


\section{DERECHO ELECTORAL}

mantenimiento del orden es responsabilidad de las autoridades locales en las que se delegó la toma de decisiones políticas.

Para las personas entrevistadas en estos cantones, la municipalidad es la referencia del Estado en el ámbito local y su gestión debe asemejarse a lo que implica conducir una empresa de manera eficiente y eficaz. Esta noción del Estado como empresa también se traduce en las características que les otorgan los entrevistados a los líderes locales: preparados, con un buen equipo de asesoría y, fundamentalmente, buenas ideas: "Hay que pensar la municipalidad como la gerencia que debe ordenar al cantón", nos dijo don Jorge en San José (comunicación personal, 5 de febrero de 2018).

En este sentido, el vínculo que se gestiona entre las y los ciudadanos con los Gobiernos locales se fundamenta en un sistema de rendición de cuentas en torno a la prestación de los servicios tradicionalmente asociados a lo municipal. El voto resulta ser ese mecanismo de control, aprobación o rechazo a la manera en cómo se administra la "empresa cantonal", de forma que su uso se hace desde una postura instrumental vinculada estrictamente a los réditos e incentivos individuales de los ciudadanos. El ejercicio de este momento, si bien es reconocido como fundamental, es limitado desde la perspectiva de las personas consultadas; cada vez más el desencanto con la política y la desvinculación con la realidad local se traducen en menor participación electoral de las personas.

\section{RefleXión final}

Al inicio del artículo se planteó el desafío de analizar las distintas dinámicas discursivas que se presentan en los relatos y prácticas de 20 personas entrevistadas en torno a las elecciones municipales del 2016. Así se identificaron núcleos discursivos medulares que dan cuenta de la relación estrecha entre el comportamiento político de las personas, sus formas de vinculación con las personas, los referentes y expectativas que depositan en la institucionalidad pública y las condiciones materiales desde donde construyen sus identidades.

Tal y como lo sostienen los relatos recabados a lo largo de esta investigación, la democracia sigue siendo parte fundamental de lo que las personas entrevistadas asocian a la identidad costarricense. La participación política pensada a través del voto y el respeto por la institucionalidad pública, articulada en función del Estado de derecho se sostienen en los discursos como 


\section{DERECHO ELECTORAL}

núcleos que dan sentido a la manera en la que se toman las decisiones en el país. A pesar de que existen diferencias importantes entre las regiones visitadas, lo cierto es que el componente procedimental del sistema político perdura en las prácticas ciudadanas. Las grietas, fugas y tensiones desarrolladas en párrafos anteriores aparecen principalmente cuando se indaga en el detalle de las construcciones de significado que le dan las personas a estos conceptos, desde las narrativas sí, pero también desde sus prácticas cotidianas.

La libertad y la igualdad son los valores centrales con los cuales las personas asocian la forma de organización política en el país; sin embargo, se presentan variaciones en los relatos en cuanto al peso que se le otorga a cada uno de estos valores como pilares de la democracia. En ese sentido, en aquellas comunidades en donde la municipalidad resulta una estructura gubernamental más cercana y se reporta la solidaridad como una actitud deseable de la ciudadanía, sobresale la igualdad como un pilar fundamental de la organización política democrática. En estos relatos también son evidentes los rasgos identitarios tradicionales, dentro de los cuales sobresalen el amor al trabajo, la solidaridad, el diálogo y el respeto a las reglas. Por otro lado, hay un grupo de relatos que dan mayor importancia a la libertad como pilar central. En este grupo se presenta una mayor cercanía con las estructuras del Gobierno central y una creciente lejanía con los Gobiernos locales, aunado a vinculaciones más débiles con el contexto comunitario.

Al profundizar en las prácticas, estas distinciones tan evidentes en el relato se diluyen en un piso común caracterizado por un desencanto con la política, y falta de participación en espacios políticos más allá del voto. La defensa del "mientras no se metan conmigo yo no me meto con nadie" se refleja fuertemente en algunos de los relatos y permite interrogar la inmanencia con la que se ha construido el discurso de la igualdad y la solidaridad del ser costarricense. Estas contradicciones son en sí mismas concluyentes, pues nos permiten ver las grietas de un imaginario político histórico que no se traduce en la práctica de manera consecuente ni adquiere los mismos significados para todas las personas.

Aún no es posible asegurar que existen diferencias categóricas y sustanciales entre los discursos y prácticas de personas que habitan en comunidades urbanas, que aquellas que habitan en contextos rurales; para esto será necesario profundizar en nuevos estudios que superen la corta duración y vayan reconstruyendo la producción de subjetividades en perspectiva política e histórica. De momento, lo que parece emerger de esta investigación es que 


\section{DERECHO ELECTORAL}

la participación electoral de las personas se ve incentivada en la medida en que los sujetos perciben que su voto se traduce en beneficios directos para ellos o sus familias particularmente en la medida en que les permite acceder a mejores condiciones o mantener las que ya tienen.

Igualmente, los textos reflejan una relación directa entre ciudadanía e identidad. Así, ese imaginario político que sustenta el discurso democrático hegemónico parece que poco a poco se aleja de los elementos con los que se identifican las personas, al menos, desde sus prácticas. Esta ciudadanía que se produce en relación con la democracia procedimental no se reconoce como sujeta de transformación social, sino más bien como expectante de un Estado al que le demanda el asegurar condiciones mínimas de seguridad y crecimiento. Estos hallazgos abren la ventana para plantear nuevas investigaciones que den cuenta de los procesos de producción de subjetividades en relación con las formas de participación política, partiendo de la premisa de que los discursos históricos nacionales penetran de manera desigual el territorio, y se entremezclan con lógicas y dinámicas particulares que emergen desde las escalas locales y comunitarias.

\section{REFERENCIAS BIBLIOGRÁFICAS}

Alfaro, R. (2002). Elecciones municipales y debilitamiento del respaldo electoral bipartidista en Costa Rica. Período 1986-2002. Anuario de Estudios Centroamericano, 28(1-2), 89-135.

Alfaro, R. y Gómez, S. (2016). Análisis del proceso electoral municipal 2016. Ponencia para el vigésimo segundo informe del Programa Estado de la Nación de 2015. Recuperado de https://estadonacion.or.cr/files/biblioteca virtual/022/ Fortalecimiento/Alfaro-Redondo\&Gomez-Campos_2016.pdf

Álvarez, L. (2010). El mito democrático costarricense y su impacto en la constitución de la práctica política en periodos de conflicto social. (Tesis de maestría). Facultad Latinoamericana de Ciencias Sociales, México.

Álvarez, L. (2015). El impacto de 30 años de reformas neoliberales en la percepción ciudadana de la relación entre democracia y bienestar humano en Costa Rica. Informe presentado para el Consejo Latinoamericano de Ciencias Sociales. CLACSO. Recuperado de http://biblioteca.clacso.edu.ar/ clacso/becas/20140901112842/LauraAlvarezGarroArticulofinal.pdf

Álvarez, L. et al. (2015). De la democracia liberal a la soberanía popular: articulación, representación y democracia en América Latina. Buenos Aires: CLACSO. 


\section{DERECHO EIECTORAL}

Álvarez, L. (2018). Democracia y sus contraconceptos durante la década de 19501959 en Costa Rica. Revista de Historia Diálogos, 19(1), 15-46.

Álvarez, L. (2010). La democracia liberal-procedimental. Un análisis del concepto desde la teoría posfundacional. (Tesis de Doctorado). Universidad Autónoma Metropolitana, México.

Cascante, M. (2016). Elecciones Municipales 2016: Datos para el análisis del sistema de partidos multinivel. Revista de Derecho Electoral, (22), 222-244.

Cascante, M. y Pignataro A. (21 de febrero de 2015). Los electorados de la democracia costarricense y las elecciones de 2018. Semanario Universidad, p. 24. Recuperado de https://semanariouniversidad.com/opinion/los-electorados-lademocracia-costarricense-las-elecciones-2018.

Centro de Investigación y Estudios Políticos, CIEP (2018). Entrevistas realizadas para el análisis del proceso electoral municipal 2016 (Documento del proyecto Participación y abstención electoral en Costa Rica, documento inédito)

Díaz, J. (2014). Activos, pasivos y apáticos: imaginarios de la población costarricense sobre la política y la democracia. Revista Rupturas, 4(2), 100-122.

Díaz, J. y Solís, M. (2010). Percepciones de la ciudadanía costarricense en la primera década del siglo XXI sobre política y democracia. Ponencia presentada en el XII Congreso de la Sociedad de Latinoamericana sobre estudios de América Latina y el Caribe. Heredia, Universidad Nacional de Costa Rica.

Güendell, H. (2009). Dialéctica del imaginario nacional costarricense, orígenes y alcances sobre el sentido de nuestra identidad cultural contemporánea. Revista de Ciencias Sociales, 47(122), 32-37.

Hall, S. (1989). The Hard Road to Renewal. Thatcerism and the crisis of the left. New York: Verso.

Lackoff, G., Johnson M. (2003). Metaphors we live by. Chicago: Chicago University Press.

Láscaris, C. (1992). El costarricense. San José: Educa.

Macpherson, C. 1997. La democracia liberal y su época. Madrid: Alianza Editorial.

Molina, I. y Palmer, S. (2000). Educando a Costa Rica. San José: Editorial Porvenir.

Mora, S. et al. (2014). Entre el apoyo a la democracia y el autoritarismo en Costa Rica. Anuario de Estudios Centroamericanos, (40), 37-60. 


\section{DERECHO ELECTORAL}

Pignataro, A. y Treminio, I. (2015). Jóvenes y democracia: Comportamiento electoral y actitudes políticas en Costa Rica. Revista de Derecho Electoral, (20), 309-343.

Programa Estado de la Nación (2017). Informe del Estado de la Nación 2016. San José, C.r. Proyecto Estado de la Nación.

Salazar, S. (2009). Matando hormigas: democratización y seguridad en El Salvador. De los Acuerdos de Paz de 1992 a las políticas de seguridad ciudadana del gobierno de Francisco Flores (1999-2004). (Tesis de Maestría). Universidad de Costa Rica. San José, Costa Roca.

Sojo, C. (2010). Igualiticos. La construcción social de la desigualdad en Costa Rica. San José: Flacso Costa Rica-PNUD.

Solís, M. (2006). La institucionalidad ajena. San José: Editorial UCR.

Raventos, C. et al. (2005). Abstencionistas en Costa Rica: ¿Quiénes son y por qué no votan? San José: Editorial de la Universidad de Costa Rica.

Robinson, W. (2011). Conflictos transnacionales: Centroamérica, cambio social y globalización. San Salvador: UCA.

Rodríguez, J. M. (1990). El concepto de democracia en América Latina. Revista de Ciencias Sociales (48), 7-15. 